\title{
Liderazgos militares y estrategias de poder. Salta 1814-1821*
}

\section{Military leadership and power strategies. Salta 1814-1821}

\author{
Sara Emilia Mata \\ CONICET- Universidad Nacional de Salta, Argentina
}

Recepción: 30 Julio 2020

Aprobación: 08 Noviembre 2020

Publicación: 13 Noviembre 2020

Cita sugerida: Mata, S. E. (2020). Liderazgos militares y estrategias de poder. Salta 1814-1821. Anuario del Instituto de Historia Argentina, 20(2), e121. https://doi.org/10.24215/2314257Xe121
Resumen: A partir de la derrota del Ejército Auxiliar del Perú en Vilcapugio y Ayohuma a fines de 1813, el Ejército Real del Perú ocupó por segunda vez la Ciudad de Salta. La estrategia diseñada por Dorrego e implementada por San Martín de desarrollar en territorio salto-jujeño una guerra de recursos similar a la que tenía lugar en las provincias del Alto Perú favoreció el retorno de Martín Miguel de Güemes a las filas del Ejército Auxiliar y su designación como jefe de la vanguardia para concretarla. Entre 1814 y 1821, año de su muerte, el protagonismo político y militar de Güemes contó con leales adhesiones e importantes oposiciones por parte de los jefes de las milicias locales como la de los Infernales, cuerpo de línea organizado por el gobernador en setiembre de 1815. Es por ello que resulta de interés abordar las estrategias que le permitieron liderar la guerra, pero también observar las contradicciones y disputas que se dirimieron en la esfera militar construyendo y sosteniendo diferentes proyectos políticos.

Palabras clave: Liderazgo, Poder, Salta.

Abstract: After the defeat of the Peruvian Auxiliary Army in Vilcapugio and Ayohuma in late 1813, the Royal Peruvian Army occupied the City of Salta for the second time. The strategy designed by Dorrego and implemented by San Martín to develop in the Salto-Jujeño territory a war of resources similar to that took place in the provinces of Alto Peru favored the return of Martín Miguel de Güemes to the ranks of the Auxiliary Army and his appointment as Head of the Vanguard. Between 1814 and 1821 , the year of his death, the political and military prominence of Güemes enabled loyal support and important oppositions by the Heads of the local militias as of the Infernales, a Command Corp organized by the Governor in September 1815. In this sense, it is proposed to address the strategies that empowered him to lead the war, but also to observe the contradictions and disputes that were addressed in the military sphere by building and sustaining different political projects.

Keywords: Leadership, Power, Salta.

Sacudió en fin esta Provincia el abominable Yugo del cruel Güemez, monstruo entre los tiranos (...) Oprimida y rodeada de bayonetas sufría con paciencia sus destrozos (...) Ya queda este por clamor general de todo el Pueblo, Tropas y Campaña, arrojado de la Magistratura que no merecía y borrado en el todo del Catálogo de Ciudadano e indigno de la mejor indulgencia. ${ }^{1}$ 
El 24 de mayo de 1821 el Cabildo de Salta intentó sin éxito destituir a Martín Miguel de Güemes, gobernador de la provincia de Salta. Ante el fracaso, la elite opositora, con la complicidad de algunos jefes de milicias y de la División de Infernales, propició el ingreso de una partida realista que logró sorprenderlo y herirlo de muerte en junio de 1821. El atentado fue una clara muestra de su debilidad política, luego de siete años de guerra, favorecida por quienes conservaban adhesión encubierta a la causa del rey, pero sobre todo por aquellos que veían en la movilización rural y en la "insolencia de la plebe" un peligro para sus prerrogativas, y fundamentalmente para sus intereses, a la vez que ansiaban normalizar el comercio con las "provincias de arriba", cuyas ciudades se encontraban en poder de los realistas (Mata, 2004). Si bien la necesidad de disciplinar a la plebe, recuperar el control sobre peones y arrenderos y restablecer el comercio con el Alto Perú fue una prioridad para un sector importante de la elite de Salta, no es menos importante, en este trágico desenlace, la trama política y las disputas de poder que excedían a la provincia de Salta y que signaron su gestión militar y su gobierno. ${ }^{2}$

La profunda animadversión hacia la figura y el gobierno de Güemes, expresada sin tapujos en la proclama del Cabildo y reiterada en las memorias de sus contemporáneos, contrasta con la adhesión y lealtad inquebrantable y sin fisuras que quienes le denostaban atribuían a la "plebe". Esta imagen de lealtad inquebrantable por parte de la "plebe", particularmente la de los hombres que componían los escuadrones gauchos, debe ser reconsiderada. Si bien entre 1814 y 1821 el protagonismo político y militar de Güemes contó con leales adhesiones, también se opusieron a su gestión, además de sectores de la elite salto-jujeña, jefes y comandantes militares tanto de las milicias provinciales o escuadrones gauchos como de la División Infernales de Gauchos de Línea, que organizara en setiembre de 1815.

Indagar acerca de la construcción de poder, tanto militar como político, que posibilitó la movilización y la militarización de la sociedad durante la Guerra de Independencia en Hispanoamérica, requiere también estudiar las razones de esa movilización, las múltiples circunstancias que la hicieron posible. Una significativa bibliografía ha dado cuenta de estas movilizaciones y movimientos insurreccionales. ${ }^{3}$ Sin embargo, estudiar estas insurrecciones focalizando el análisis en la gerencia de amplios sectores rurales y urbanos que participaron en ellas resulta insuficiente para explicar la construcción de los liderazgos que con diferentes relevancias canalizaron esas movilizaciones.

Con el fin de indagar acerca de la construcción de estos liderazgos, consideramos interesante retomar algunos conceptos en relación con el poder. En este caso, los propuestos por Mann (1991:21-23), para quien "el poder es la capacidad para perseguir y alcanzar objetivos", y en especial su clasificación de poder extensivo como "la capacidad para organizar a grandes cantidades de personas en territorios muy distantes a fin de actuar en cooperación con un mínimo de estabilidad". A esta clasificación podríamos sumar el concepto de poder autoritario, que "es al que aspiran efectivamente grupos e instituciones. Comprende unas órdenes definidas y una obediencia consciente".

Estos conceptos resultan centrales para esbozar las configuraciones del poder en el contexto de la dinámica de la guerra iniciada en 1810 -particularmente entre 1814 y 1821 - en la provincia de Salta. Para ello será necesario observar las estrategias destinadas a construir y/o fortalecer un capital político que, tal como lo define Bourdieu (2001, p. 90), "es una forma de capital simbólico, crédito fundado en las innumerables operaciones de crédito por las cuales los agentes confieren a una persona socialmente designada como digna de confianza, los poderes que ellos le reconocen". Su posesión legitima entonces la autoridad. Es desde estas perspectivas teóricas que nos interesa indagar sobre el capital político de Martín Miguel de Güemes y su capacidad de ejercer poder en un territorio amplio y heterogéneo, que incluía, además de la jurisdicción de Salta y Jujuy, a Tarija, Atacama y Cinti.

Planteamos que no solo construyó su liderazgo a partir de la insurrección, que desde 1814 tiene lugar en el valle de Lerma y de la cual se apropia (Mata, 2002), sino que el mismo se nutrió de las movilizaciones propiciadas por líderes locales de carácter rural y de su relación con oficiales del Ejército Auxiliar, que operaban en la vanguardia. Con ellos ejecutó acciones defensivas y ofensivas desde la legitimidad que le 
otorgaba su condición de jefe de la vanguardia del Ejército Auxiliar y de gobernador de la provincia de Salta. Los alcances y límites de su poder estarían directamente vinculados a la particular configuración de las fuerzas militares bajo su mando, las complejas relaciones entre ejército y milicias y las contradicciones y disputas que se dirimían en la esfera militar, y que respondían, en algunas ocasiones, a diferentes proyectos políticos, y en otras, a preeminencias de poder territoriales.

Trataremos así de abordar las estrategias que le posibilitaron acumular capital político y construir y ejercer poder, atendiendo tanto a los antecedentes de militarización en la jurisdicción de Salta, como a la participación de referentes locales y oficiales del ejército auxiliar en la movilización y militarización iniciada en 1814 en el extenso escenario de una guerra de recursos durante siete años.

\section{LA MILITARIZACIÓN Y SUS LÍDERES}

La organización de ejércitos destinados a sostener la autoridad de la Junta de Gobierno instalada en Buenos Aires en mayo de 1810 ha merecido en estos últimos años un creciente interés en la agenda historiográfica, ${ }^{4}$ dedicada a estudiar los problemas derivados de su organización, que incluía, junto a los cuerpos regulares existentes en la colonia, la creación de cuerpos de líneas y la organización de milicias voluntarias (Fradkin, 2012). La importante movilización social, resultante de una militarización estrechamente vinculada a diferentes proyectos políticos, generó, junto con los intereses personales que suponían las prerrogativas de una carrera militar -tal como la planteara Halperín Donghi (1972)-, conflictos permanentes que afectaban la capacidad de mando de quienes ejercían la conducción (Morea, 2015a).

El Ejército Auxiliar del Perú, destinado a sujetar la autoridad de la Junta de Buenos Aires a las provincias del interior del Virreinato del Río de la Plata, no estuvo exento hasta su disolución, en 1820, de estas dificultades. A este ejército se incorporó Martín Miguel de Güemes en 1810. 5 Su relación con las jefaturas mantuvo desavenencias, primero con Juan Ramón Balcarce y luego con Manuel Belgrano, razón por la cual en enero de 1814 se encontraba en Buenos Aires. ${ }^{6}$ Regresó a las filas del Ejército Auxiliar en febrero de ese año, conduciendo un cuerpo de caballería a solicitud de José de San Martín. A partir de 1814, y hasta 1821, Güemes fue adquiriendo protagonismo, a la vez que generaba oposiciones que se expresaron no solo en la elite sino también en las jefaturas militares bajo su mando. Durante esos siete años, signados por la amenaza constante de las incursiones realistas, es interesante analizar su habilidad para ejercer autoridad aglutinando voluntades, ${ }^{7}$ y para construir el capital político que le permitió ejercer el cargo de gobernador y jefe de la vanguardia hasta 1821. Este recorrido, sin embargo, requiere focalizar en otros liderazgos y jefaturas que actuaron como intermediarios en el entramado que posibilitó la militarización en Salta, los cuales representan aspiraciones de carácter político y social individuales y comunitarios relacionados con intereses territoriales (Ortiz de Rozas, 2017).

La historiografía local ha considerado a Güemes como el artífice exclusivo de la insurrección y movilización, particularmente rural, de la provincia de Salta, y ha ensalzado su figura y su gesta en la Guerra de Independencia. ${ }^{8}$ De esta manera, se afirma que los "gauchos", como comenzaron a ser denominados los paisanos de la campaña movilizados a partir de 1814, obedecían ciegamente sus órdenes, al igual que los jefes de las milicias que lo secundaban. Esta historiografía, que concibe como "hacedores de la historia" a aquellos que la protagonizaron desde espacios de poder político, coincide paradójicamente con los detractores del gobernador, quienes lo consideraban el único responsable de la insurrección social (Mata, 1999 y 2002). Es indudable que sus esfuerzos para resistir y hostigar a los enemigos habrían de granjearle a Güemes el apoyo de quienes se encontraban bajo su mando. Sus detractores interpretaron, obviamente, esta conducta de manera negativa. Por ejemplo, para el general Paz buscó identificarse con los gauchos con la finalidad de seducirlos, mientras que, para quienes en 1821 propiciaron su muerte, imitó a la muchedumbre fomentando sus vicios. ${ }^{9}$ 
Esta imagen de Güemes como el hacedor de la insurrección y la militarización se inició tempranamente. En setiembre de 1814, poco después del retiro de las tropas realistas del general Pezuela hacia el Alto Perú, José Rondeau, al mando del Ejército Auxiliar del Perú, en un oficio dirigido al Directorio en Buenos Aires afirmaba que "el Comandante Güemes no tenía a su disposición más que unos pocos soldados y un considerable número de paisanos que él mismo supo reunir, entusiasmar, darles dirección y empeñarlos en continuas guerrillas con el mejor suceso", a la vez que solicitaba se le recompensara con el grado de coronel del Ejército. A pesar de esta contundente afirmación, que otorgaba a Güemes los méritos casi exclusivos de la insurrección del valle de Lerma, no dudó en solicitar "una particular recomendación al benemérito comandante de gauchos don Pedro José de Zavala: éste ha sido el principal promovedor de la guerra que han hecho aquellos al enemigo y el que la ha sostenido con un tesón infatigable". ${ }^{10}$ Efectivamente, había sido Pedro José de Zavala el promotor de la guerra de recursos, aunque no el único, que se inició a comienzos de enero de 1814, un mes antes de la llegada de Güemes al Ejército Auxiliar y de su designación como jefe de la vanguardia. Si analizamos con detalle este oficio de Rondeau, es posible observar que, mientras reconocía en Güemes una eficiente labor en la coordinación de los grupos insurgentes que operaban en el valle de Lerma y la frontera con el Chaco, señalaba con toda justicia que quienes iniciaron la movilización de la población rural en el valle de Lerma fueron Pedro José de Zavala y Alejandro y Luis Burela, todos ellos medianos propietarios y jefes de milicias locales que habían también colaborado en la batalla de Salta en 1812 .

Es importante en este punto recordar que la decisión de desarrollar en territorio salto-jujeño una guerra de recursos -similar a la que desde 1812 tenía lugar en el Alto Perú- había sido propuesta a José de San Martín por Manuel Dorrego, destacado oficial del Ejército Auxiliar, quien con sus avanzadas auxiliaba a los levantamientos campesinos del valle de Lerma junto con las milicias de Salta, que habían retrocedido hacia Tucumán con Belgrano cuando los realistas invadían y ocupaban Salta y Jujuy (Mata, 2002).

En el mencionado plan, presentado a San Martín el 2 de febrero de 1814, Dorrego proponía a Pablo Latorre, capitán de Partidarios, ${ }^{11}$ para que fuera designado al mando de cincuenta hombres de tropa, y aconsejaba nombrar a Pedro Zavala

... capitán del Bañado, Chicoana y Gauchipas y quedando a su arbitrio el elegir los subalternos, que podría reunir una porción muy considerable de paisanos (...) Tanto el paisanaje como la tropa, puede ponerse a disposición del coronel don Pedro José Saravia, teniendo consigo a su hijo don Apolinar y a su pariente don Saturno. ${ }^{12}$

Como puede observarse, Manuel Dorrego no menciona a Güemes, quien por solicitud de San Martín en diciembre de 1813 había ascendido a teniente coronel. Si bien este aún no había arribado a Tucumán, es poco probable que no supiese que se esperaba su llegada con los refuerzos de caballería solicitados por San Martín. A su juicio, indudablemente existían en la jurisdicción de Salta y Jujuy jefes, como Pablo Latorre, en quienes se podía confiar el desarrollo de la guerra de recursos.

El apego de San Martín al reconocimiento de las jerarquías militares y la probable recomendación de Juan Martín de Pueyrredón pudieron haber sido, entre otras, las razones por las cuales Güemes fue elegido para ser el jefe de la vanguardia. ${ }^{13}$ Seguramente también pesó en su designación su condición de natural de Salta y sus antecedentes militares, por los cuales contaba con conocimiento del territorio y con vinculaciones sociales, no solo en la jurisdicción de Salta sino también en Tarija, Jujuy y Orán, resultantes de su participación activa en las filas del Ejército Auxiliar a partir de 1810. Instalado el cuartel de vanguardia en el río Pasaje, en las Conchas, próxima a la Frontera del Rosario, al sureste de la jurisdicción de la ciudad de Salta, Güemes coordinó con A polinario Saravia, jefe de las milicias del valle de Lerma, y con Zavala y Burela el hostigamiento a las partidas realistas con el apoyo - para organizar milicias voluntarias en la frontera- de José Francisco Gorriti, hacendado del lugar, y del pardo, zambo o mulato Panana, quien ya se había destacado en la batalla de Salta del 20 de febrero de $1813 .^{14}$

Si la movilización del valle de Lerma en los primeros meses de 1814 tenía sus referentes en Pedro José de Zavala y Luis Burela, en la amplia frontera salto-jujeña -así como en Humahuaca, San Andrés, Yavi, 
Orán y Tarija - se destacaban Pablo Latorre, Manuel Eduardo Arias, Eustaquio Méndez, Juan Manuel Rojas, Eustaquio Medina, Francisco de Uriondo, José Gabino Sardina, entre muchos otros de menor relevancia. Algunos dirigían partidas de milicias voluntarias y otros revistaban en las filas del Ejército Auxiliar. Todos enfrentaron sin éxito al Ejército Real del Perú en su marcha hacia Salta y Jujuy y hacia Tarija y Orán.

Tal como lo señala Dámaso Uriburu ([1857] (1960), pp. 701-703), y como era costumbre y norma consuetudinaria, las milicias elegían a sus jefes, lo que seguramente ocurrió, por lo menos en 1814, en el valle de Lerma, al igual que en el resto del territorio donde se movilizaron voluntarios para resistir la invasión realista. Será precisamente en el valle de Lerma donde el liderazgo de Güemes comenzará a construirse y se fortalecerá en su enfrentamiento con el directorio en Buenos Aires y con Rondeau, quien, luego de alabarlo y atribuirle la movilización, intentará desplazarlo como jefe de la vanguardia y reorganizar las milicias en Salta por intermedio de José Antonino Fernandez Cornejo, a quien nombró gobernador de la provincia luego de la retirada del ejército de Joaquín de la Pezuela y de la decisión de Gervasio de Posadas de dividir la Gobernación Intendencia creando las provincias de Tucumán y de Salta, en la cual estaban comprendidas Jujuy, Orán, Tarija y Santa María (Mata, 2002).

El universo de los integrantes de cuerpos de línea, o de "milicias" o "escuadrones gauchos", como pasaron a denominarse estas a partir de 1815, fue muy heterogéneo, tanto por su condición social como étnica. Participaron de ellas indios, mestizos, blancos pobres y negros, libres y esclavos. Tal como consta en el acta del Cabildo de Salta del 29 de octubre de 1814:

la fortuna de estos infelices se reducía absolutamente a un corto número de ganados vacuno y caballar. Dispuestos a hacer la guerra, sin más armas que los propios brazos, no ha habido un hombre que no se alistase en el número de soldados voluntarios, que han militado bajo el nombre de gauchos. ${ }^{15}$

Las jefaturas de estos cuerpos militares también reconocen orígenes diversos. Entre ellos algunos eran propietarios rurales de diferente condición económica y social, con inclusión de pequeños productores y artesanos. Cabos, sargentos y capitanes hasta comandantes de milicias procedían de la plebe. En el transcurso de la guerra será posible observar la posibilidad, para quienes procedían de la denominada "plebe" o de los sectores medios de la sociedad, de revistar como oficiales y hacer carrera militar en los Cuerpos de Líneas creados por Güemes, o en aquellos del Ejército Auxiliar que continuaron operando bajo sus órdenes. ${ }^{16} \mathrm{Si}$ bien es imposible trazar la trayectoria de todos ellos, puede observarse su dinamismo y su importancia en la movilización. A través de los partes y los oficios que elevan a sus superiores, es posible reconocer toda la cadena de mando, las dificultades y las disputas, particularmente en 1814 y 1817 , cuando tuvieron lugar las dos invasiones realistas, que ocuparon las ciudades de Salta y Jujuy y que respondían a un plan militar destinado a sofocar la revolución rioplatense.

\section{LOS BRAVOS DEFENSORES DE LA PATRIA}

La designación de Güemes en la vanguardia del Ejército instalada sobre el río Pasaje puso bajo su mando a las avanzadas del Ejército Auxiliar que operaban en la frontera, en Yavi, la quebrada de Humahuaca y Tarija, con el apoyo de grupos milicianos y voluntarios locales. De igual modo, en virtud de su cargo, sumaba las milicias voluntarias del valle de Lerma, que respondían a Zavala y a Apolinario Saravia, a aquellas que con José Francisco Gorriti organizara en la frontera del Rosario. El éxito logrado por estas milicias, que hostigaban a las partidas realistas que se aventuraban fuera de la ciudad para aprovisionarse de ganado y víveres, junto con la rendición de Montevideo en junio de 1814 y con la precaria situación en que se encontraban las ciudades altoperuanas -amenazadas por el accionar de las guerrillas coordinadas por Juan Antonio de Arenales e Ignacio Warnes- forzó el retiro de Joaquín de la Pezuela. Sin embargo, la recuperación de las ciudades de Salta y Jujuy fue atribuida exclusivamente a la enérgica resistencia desplegada en el valle de Lerma y en la frontera, incluyendo Jujuy y Tarija y fue capitalizada por Güemes en su condición de jefe de la vanguardia. A partir de ese momento comenzará a construir el capital político que 
finalmente le permitirá acceder al gobierno de la provincia de Salta y a desplegar autoridad sobre las milicias y Cuerpos de Línea que operaban en un amplio territorio, que incluía, después de 1816, al partido de Atacama ${ }^{17}$ y a los grupos insurgentes altoperuanos (Mata, 2008).

En este sentido, es interesante observar cómo rápidamente responderá a la desconfianza que la movilización despertaba en el Directorio y en Rondeau, quienes consideraban que la misma podía ser cooptada por algunos jefes militares sospechados de acordar políticamente con José de Artigas para desafiar la autoridad del Directorio (Mata, 2017). Estos resquemores se iniciaron pocos días después del informe positivo que Rondeau elevara al Directorio acerca de la actividad desplegada por Güemes como jefe de la vanguardia, cuando este reclamó a Martín Rodríguez por las desavenencias ("no sé el motivo, entre el Regimiento de V.S y los bravos defensores de la patria”) solicitándole no incomodara y liberase a quienes llamaba "mis gauchos". ${ }^{18}$ Una preocupación constante de Güemes fue la de reafirmar, en cada ocasión que fuera propicia, la idea de que era él quien había "levantado toda la campaña”, y la de referirse a los hombres movilizados como "mis gauchos", tal como lo hacía con los hombres que respondían a Zavala, reclutados por este (Mata, 2004a).

No solo hizo suyo el reclamo de Zavala, tal como lo prescribía el Reglamento de Milicias, sino que también lo apoyó, asumiendo de esta manera, tanto discursivamente como en la práctica, la representación de esa movilización iniciada previamente a su designación como jefe de la vanguardia. Es asimismo reveladora su amenaza cuando advierte sobre no "incomodarlos", una amenaza que utilizará en reiteradas ocasiones y en diferentes circunstancias (Mata, 2004). No extraña entonces la orden del director supremo a José de Rondeau de: "sofocar en su raíz el germen de la discordia, sin permitir tome cuerpo la división para no ser envueltos en las desgracias que por iguales principios lamentamos hoy en la banda Oriental". ${ }^{19}$ Solicita, además, que separase a Güemes del Ejército Auxiliar y que lo envíe con una comisión a Buenos Aires. No solo esta última demanda no fue satisfecha, sino que tampoco prosperaron los intentos de desplazar a Güemes de la organización de las milicias. ${ }^{20}$

El avance del Ejército Auxiliar hacia el Alto Perú con la participación de Güemes, quien luego de ser destituido por Rondeau se había autoproclamado comandante de los Paisanos de Salta, resultó clave para consolidarlo en el poder militar y político. Las milicias gauchas que le siguieron hasta Puesto del Marqués en abril de 1815 no superaban los 1000 hombres, de los cuales tan solo 500 correspondían a las milicias del valle de Lerma y del Calchaquí. ${ }^{21}$ En Puesto del Marqués, luego de obtener un triunfo sobre las fuerzas realistas, Güemes comprendió que no era conveniente forzar a las milicias a continuar el avance hacia el Alto Perú. La deserción y el descontento hubieran erosionado su autoridad, ya que las milicias, si bien resultaban adecuadas para la guerra defensiva, eran reacias a alejarse de su territorio (Fradkin, 2010). La decisión militar de regresar a Salta con las milicias fue también un acierto político. Necesitaba fortalecerse políticamente y legitimar su mando militar; para ello buscó ser designado gobernador de la provincia de Salta aprovechando la coyuntura que ofrecía la vacancia del mencionado cargo $^{22}$ y la fortaleza que le brindaban los milicianos, a los cuales proveyó de 600 fusiles tomados de la maestranza de Jujuy cuando regresaba del Puesto del Marqués en abril de 1815. El apoyo que recibió en esta ocasión involucró, sin dudas, a estas milicias. Su designación, realizada por el Cabildo de Salta con voto secreto, según consta en el acta del 6 de mayo de 1815, no brinda mayores detalles de los argumentos vertidos acerca de la conveniencia o no de esta designación (Marchionni, 2019). El acta tampoco refiere quién propuso su nombre, y de su lectura se percibe la coacción ejercida por "el pueblo que se hallaba congregado fuera de la sala capitular que pedía se nombrase un gobernador" ${ }^{23}$

Diferentes estrategias irían nutriendo el capital político que le permitiría presentarse como depositario de un poder absoluto ante esas milicias. Una decisión importante, resistida por los Cabildos de Salta y Jujuy, fue el reconocimiento del fuero militar permanente para todos los milicianos o gauchos. Otra determinación fundamental fue organizar, poco después de ser elegido gobernador, un cuerpo de línea en el cual incluyó, en 
los cargos más relevantes, a quienes demostraron mayor capacidad de movilizar en 1814, cuando resistieron la invasión del Ejército Real del Perú. Efectivamente al elevar al gobierno en Buenos Aires la propuesta de creación de la División Infernal de Gauchos de Línea, en setiembre de 1815, argumentaba: "aquellos héroes que bajo la denominación de gauchos, han contraído tan recomendables, voluntarios y desinteresados servicios (...) se me han reunido para emplearse absolutamente en el servicio formando un cuerpo de línea”; y por lo mismo solicitaba la aprobación "de este cuerpo compuesto de voluntarios patriotas". ${ }^{24}$ Es innegable la importancia de esta decisión, que, además de otorgar a algunos de ellos un reconocimiento social que hasta ese momento no habían recibido, brindaba la posibilidad, a quienes pasaron a revistar en este Cuerpo de Línea, de gozar de salario y uniforme. Una manera eficiente de sumar reconocimiento y lealtad a su autoridad. ${ }^{25}$

Entre los jefes y oficiales de este Cuerpo de Línea, organizado en dos escuadrones, nombró a Pablo Latorre teniente coronel y comandante del Primer Escuadrón. Obviamente, para Güemes era importante contar con su apoyo, ya que disponía de una red de relaciones en la frontera de particular importancia para movilizar milicias voluntarias. Tampoco resulta sorprendente la designación de Vicente Panana, ${ }^{26}$ hasta ese momento sargento de las milicias voluntarias, como capitán de la Primera Compañía del Primer Escuadrón, quien se había destacado no solo en la batalla de Salta, sino también, en 1814, bajo las órdenes de Güemes. Este caso ejemplificaría la decisión, por parte de la dirigencia revolucionaria, de flexibilizar las disposiciones heredadas de la colonia, que solo abrían la posibilidad de integrar la oficialidad a miembros de las élites (Rabinovich, 2011). Para Panana, por su condición social, revistar en un Cuerpo de Línea y obtener el grado de Capitán significaba claramente un ascenso social impensado en otras circunstancias. En la plana mayor, Güemes designó sargento mayor a Apolinario Saravia. ${ }^{27}$ Luis Burela y Pedro José de Zavala fueron ascendidos en su condición de jefes de las Milicias Provinciales, que se organizaron en Escuadrones Gauchos.

Su preocupación por la creación de Cuerpos de Línea y de Escuadrones Gauchos, tanto en la jurisdicción de Salta como en la de Jujuy, ${ }^{28}$ fue la razón por la cual buscó ser designado gobernador de la provincia de Salta, cargo que le otorgaba la autoridad necesaria para tal fin. El Cabildo de Jujuy y su teniente de gobernador cuestionaron seriamente su designación alegando no haber participado en su elección. Se manifestaba así no solo la oposición al creciente poder de Güemes en el plano militar, sino también la disputa autonómica en relación con Salta, expuesta en 1811 en la Junta Grande por Juan Ignacio Gorriti, diputado por la ciudad de Jujuy, al reclamar la separación de Jujuy de Salta (Marchionni, 2008; Paz, 2004; Abbate y Burgos, 2020). La resistencia a su gobierno, y a su facultad para reclutar hombres como jefe de la vanguardia en la jurisdicción de Jujuy, no le impidió incorporar en los Escuadrones Gauchos a quienes gozaban de su confianza, como él mismo afirmara al desafiar las órdenes de Rondeau en 1814 (Mata, 2002). En febrero de 1816 cuando arreciaba su enfrentamiento con Rondeau -quien luego de ser derrotado por las milicias de Güemes avanzaba desde Salta hacia Jujuy ${ }^{29}$ y continuaba reuniendo milicias voluntarias para enfrentarlo- no dudó en afirmar que "si el Cabildo no quería este alistamiento general de gauchos de la campaña y de cívicos de la ciudad, que se hiciese cargo de la defensa de ésta”; por esto, "como en el pueblo no hay armas algunas el Cabildo accedió a que el señor Gobernador se hiciese cargo de la defensa". 30

A pesar de esta decisión del Cabildo, cuando las diferencias con Rondeau habían sido zanjadas en el Pacto de los Cerrillos, celebrado el 22 de marzo de 1816, ${ }^{31}$ el teniente de gobernador de Jujuy, Mariano de Gordaliza, en un oficio dirigido a Rondeau, le recordaba el ofrecimiento que le hiciera, de "cuatro compañías de los milicianos de ésta que aún no estaban tan apasionados por Güemes” (énfasis nuestro), y manifestaba su temor al traslado del ejército acuartelado en la ciudad de Jujuy, dispuesto en el mencionado pacto, que dejaría a "la ciudad expuesta a ser víctima de la campaña como ya se amenaza por el mayor auge que ha tomado la gauchada con esta transacción”. ${ }^{32}$

Al parecer, la adhesión a Güemes había aumentado, y, de acuerdo a los temores del teniente de gobernador de Jujuy, una de las razones sería la firma del Pacto de los Cerrillos entre Güemes y Rondeau, que admitía la incorporación de hombres del Ejército Auxiliar a las fuerzas militares que organizaba Güemes en la provincia. 
Es interesante suponer que en este mayor entusiasmo incidió también la orden de Güemes, unos días antes de finalizar el conflicto con Rondeau, a uno de los caudillos de la frontera del Río del Valle, de reunir hombres con la promesa de repartir las tierras de quienes apoyaban a Rondeau "a toda la gauchada". ${ }^{33}$

Además de otorgar el fuero militar permanente a los gauchos que integraban los escuadrones, negoció con los propietarios rurales la "eximición ínterin dure la guerra" del pago de los arriendos y los derechos parroquiales (Mata, 1999). El éxito de Güemes, en esta instancia, fue lograr que los propietarios aceptaran una situación que de hecho había comenzado a producirse a partir de 1814 y que se intensificaría en los años siguientes cuando, además de no pagar arriendos, los peones se negarían a prestar servicios a los patrones y comenzarían a ocupar tierras sin autorización de los propietarios (Mata, 2004).

Particularmente en el valle de Lerma, donde se concentró el mayor número de hombres incluidos en los Escuadrones Gauchos, se observa con mayor fuerza el conflicto en torno a la propiedad y el control social. El aumento de la población, que puede inferirse por el significativo número de gauchos enrolados en los escuadrones, ${ }^{34}$ se vincularía a la presencia en ellos de altoperuanos y vecinos de otras jurisdicciones de las Provincias Unidas del Río de la Plata que permanecieron en Salta cuando el derrotado ejército de Rondeau se retiró hacia Tucumán en 1816. Coincidentemente, en 1818 Güemes promulgaba un bando por el que ratificaba el goce del fuero militar y el no pago de arriendos ni prestaciones de servicios al patrón, en un claro y doble mensaje destinado a los gauchos: reconocía los derechos que ellos habían adquirido por las armas, a la vez que se arrogaba la potestad de ser el garante de esas prerrogativas. ${ }^{35}$ Esta imagen protectora -que él mismo se preocupa por construir-, basada en el paternalismo presente en las relaciones asimétricas dominantes en la colonia, resultó exitosa. En las peticiones que los gauchos realizaron se dirigían a él como "Padre de los gauchos", expresión demostrativa del paternalismo abonado por Güemes, quien en reiteradas oportunidades se refiere a sí mismo como "Jefe, Padre y Paisano de ellos". ${ }^{36}$

Mientras los Cuerpos de Línea contaban con salario y uniforme, los gauchos milicianos solo recibían socorros cuando se encontraban en combate. Si la remuneración y los premios resultaban centrales para mantener la disciplina en el ejército y evitar la deserción (Bragoni, 2005), a quienes integraban los Escuadrones Gauchos era fundamental brindarles, cuando no estaban en acción, los beneficios derivados del desempeño de tareas requeridas para el sostén de las tropas, por las cuales eran recompensados de diferentes maneras. Los libramientos de pago permiten observar su desempeño como arrieros, leñateros, lomilleros, entre otras labores, para las cuales eran empleados y retribuidos por el gobierno. ${ }^{37}$ Abundan asimismo los testimonios de la venta de ganado, leña, velas y sal, cuyo pago Güemes ordenaba de inmediato.

De todas maneras, el recurso más contundente fue favorecer el acceso a la tierra. En 1817, cuando arreciaba la indisciplina social, Belgrano le advertía a Güemes acerca de la conveniencia de disolver la División Infernal de Gauchos de Línea. También le aconsejaba apoyar a las partidas del Ejército Auxiliar en una incursión al chaco, con lo cual podrían lograrse varios objetivos, ya que: "además de conseguir caballos y otros objetos, puede $\mathrm{Ud}$. entretener sus gentes y dándoles propiedades, adquirir riqueza real para la Provincia y el aumento de su población". ${ }^{38}$ Aparte de los beneficios que reportaría al ejército disponer de ganado tendría la posibilidad de evitar las conspiraciones en las cuales se habían involucrado algunos jefes de las milicias (Mata, 2004b), y al recompensarles con un bien tan ambicionado podía poblar y poner en producción las tierras del chaco.

Frente a la indisciplina social y la movilización su poder no fue absoluto. Los Escuadrones Gauchos, particularmente los de la jurisdicción de la ciudad de Salta, fueron indudablemente su base, a pesar de no responder directamente a su autoridad, la cual estaba mediada por los jefes de esos escuadrones. Si bien tanto desde la práctica como desde el discurso buscó construir una representación de poder sin fisuras, esto no significó que efectivamente lo lograse. Sus órdenes fueron en reiteradas ocasiones desobedecidas por quienes contaban con el mando de cuerpos militares incluidos en la vanguardia, tal como sucediese con José Antonino Fernández Cornejo. ${ }^{39}$ Pero más interesante aún que la desobediencia, en determinadas circunstancias originada por disputas previas, fue la invocación de órdenes, probablemente nunca emitidas 
por él, que animaban a desobedecer a las efectivamente formuladas. Un caso paradigmático y revelador fue la respuesta dada por el alférez de la Primera Compañía a la orden emitida por Güemes en 1821 de pagar los arriendos en la estancia La Alemania. Desafiando incluso al teniente de Gauchos de Guachipas, respondía

Prevengo a todos Uds. no me incomoden a los gauchos ni permitan que persona alguna los perturbe en sus labores, no siendo en servicio del estado. Con respecto a los arrendamientos ya saben todos que no deben pagar por orden del Gobernador, ni los señores dueños de los terrenos tienen por qué incomodar a nadie. Sobre este particular si para que no paguen se ordenó por bando y por sus oficiales así mismo deber ser para que paguen. ${ }^{40}$

Al hacer referencia al bando publicado en 1818, que mencionamos, enfrentaba la autoridad del gobernador al solicitarle otro que anulase al anterior, conociendo la imposibilidad de Güemes para emitirlo, dado el conflicto y la resistencia que conllevaría semejante disposición de su parte. La información sobre excesos, concretados o autorizados por los jefes inmediatos de los hombres movilizados en los Escuadrones Gauchos, es reiterada tanto en la jurisdicción de Salta como en la de Jujuy. Así se evidencia en el reclamo del comandante de los Gauchos de Jujuy a Mariano Benavidez, a quien le habla de hechos cometidos "sin orden del coronel [Güemes] ni mía, sino voluntariedades que no sé cómo las ha permitido el jefe de la comandancia". ${ }^{41}$

Aun cuando la elite salto-jujeña atribuyó a Güemes ser el causante del trastorno al orden social, todo indica que el poder de Güemes tenía sus límites. Estos también se manifestaron cuando se vio impedido de castigar a Vicente Panana en 1817, acusado de conspirar en su contra junto con los hermanos Moldes y otros jefes de las milicias. En esa ocasión debió contentarse con remitirlo a Buenos Aires, probablemente para evitar la rebelión de los hombres que respondían a Panana y a Moldes (Mata, 2004b). Sus esfuerzos por construir el poder autoritario (Mann,1991), indispensable para sostener una movilización eficiente frente a las incursiones realistas, resultaron exitosos; para ello se valió de las estrategias sociales y simbólicas disponibles, tales como el paternalismo y los atributos de su cargo, reafirmando desde lo discursivo representar las expectativas sociales de los hombres enrolados en los escuadrones gauchos y de garantizar en la práctica sus derechos, a la vez que recurría a los premios y compensaciones tanto materiales como simbólicas (Rabinovich, 2011, p. 56).

\section{LOS JEFES DE LA VANGUARDIA EN UN EXTENSO TERRITORIO}

Una de las decisiones de Rondeau en octubre de 1814, antes de enemistarse con Güemes y destituirlo del Ejército Auxiliar, fue disponer que el partido de Cinti y el de Tarija ${ }^{42}$ estuviesen sujetos al mando del "Comandante General de avanzadas Coronel don Martín Güemes", y dejar a cargo de Juan Antonio Alvarez de Arenales "todas las demás fuerzas de las provincias y partidos del interior que en el día se hallen libres o en adelante vayan libertándose de la opresión del enemigo, hasta la provincia de la Paz” ${ }^{43}$ Este fue el territorio, además del partido de Atacama, incorporado a la vanguardia en 1816, cuyos grupos armados y fuerzas de línea operaron coordinadas por el gobernador de Salta después de la derrota del ejército de Rondeau en el Alto Perú. Por esta razón quedaron bajo su conducción los jefes de milicias altoperuanas y los Cuerpos de Línea del mencionado ejército, a los cuales es preciso sumar aquellos jefes de milicias locales que, desde 1810, operaban tanto en Cinti como en Tarija, la Puna, la quebrada de Humahuaca, Orán y Río del Valle, estos últimos en la frontera chaqueña, donde se ubicaban los fuertes con mayor número de partidarios. Con muchos de ellos Güemes se había relacionado desde el comienzo de la revolución; otros fueron surgiendo en el transcurso de la guerra, y otros eran oficiales y soldados del Ejército Auxiliar que se incorporaron a los Cuerpos de Línea que organizó Güemes en 1816.

Un detalle interesante, que puede ofrecer pistas acerca de las razones por las cuales parte de los oficiales y tropa aceptaron incluirse, podemos encontrarlo en el interés manifestado por Güemes ante la angustiosa situación por la cual atravesaba una compañía del Ejército Auxiliar, a las órdenes de Rondeau, en su avance hacia el Alto Perú en 1814. La misma había permanecido más de seis meses en Humahuaca, "a ración y sin sueldo" como consecuencia de las desavenencias entre Alvear y Rondeau, ${ }^{44}$ cuando 
Don Martín Miguel Güemes, que estaba nombrado jefe de vanguardia, vino un día como a consolarnos el desprecio y mal trato que recibíamos, anunciándonos que él iba a pedir el mando de nuestro cuerpo, que entonces seríamos bien pagados y que nos llevaría a Tarija, donde nos formaría mil o dos mil hombres para que escogiéramos los mejores, para elevar nuestro regimiento sobre todos los del ejército. (...) Pocos días después de la marcha del Coronel Güemes a Colorados, nos mandó orden para que en el acto marcháramos sin descanso a incorporarnos... ${ }^{45}$

Entre estos jefes y oficiales del Ejército Auxiliar que decidieron permanecer en Salta luego de la derrota del Ejército de Rondeau se encontraban José María Pérez de Urdininea ${ }^{46}$ y Francisco Pérez de Uriondo. A este último Güemes le encomendó la organización del Cuerpo de Granaderos a Caballo. Su teatro de operaciones fue Tarija, donde Güemes le nombró gobernador en $1816 .{ }^{47} \mathrm{Si}$ bien Urdininea no habría de permanecer mucho tiempo en el Ejército Auxiliar del Perú ni en la vanguardia de la provincia de Salta, participó activamente durante la invasión del general realista José de la Serna en 1817, lo que da cuenta de su autoridad sobre las partidas y Cuerpos de Línea, cuya acción organizaba frente a los realistas. ${ }^{48}$

Estaban a las órdenes de Uriondo la división del Bermejo, la División de San Lorenzo y la División de Salinas, ${ }^{49}$ cuyos jefes locales habían sido fundamentales en la movilización voluntaria. Uno de ellos era Eustaquio Méndez, en Tarija, y otro Mariano Benavídez, en Río del Valle, al cual Güemes había recurrido para reunir gente con la finalidad de enfrentar a Rondeau. Si bien la relación de Uriondo con Güemes fue muy buena, su vinculación con Manuel Belgrano muestra un trato frecuente. En abril de 1817 informaba a Belgrano la recuperación de Tarija con la colaboración del jefe chiriguano Cumbay, aliado de los revolucionarios y particularmente de Belgrano, con quien, en 1813, había celebrado una alianza cuando este se encontraba en Potosí (Saignes, 2006, pp. 119-123). También llegaron con el Ejército Auxiliar, y quedaron en Salta a las órdenes de Güemes, Gaspar Aramayo y José Miguel Lanza, ambos altoperuanos y jefes de grupos insurgentes que se habían sumado al ejército de Rondeau y habían retrocedido junto con él, luego de la derrota de Sipe Sipe. José Miguel Lanza permaneció al lado de Güemes hasta que en 1821 este lo enviara a Ayopaya a reorganizar allí la División de los Valles, ${ }^{50}$ en atención a las órdenes de San Martín de iniciar una expedición al Alto Perú para cercar a las fuerzas realistas del general Pedro Antonio de Olañeta. Gaspar Aramayo, en cambio, mantuvo una estrecha relación de dependencia con Manuel Belgrano, quien lo favoreció con ascensos militares y con la delegación de Atacama (Mata, 2019), aun cuando desde luego reportaba y obedecía también a Güemes como jefe de la vanguardia del Ejército Auxiliar. Podemos observar así que, si bien Güemes estaba al mando de las fuerzas de la vanguardia del Ejército Auxiliar, oficiales como Urdininea, Uriondo y Aramayo reconocían el mando de Belgrano, mientras que jefes de milicias locales, como Manuel Eduardo Arias o Mariano Benavidez, obraban con relativa autonomía, todo lo cual en ocasiones provocó tensiones y conflictos que requerían ser superados por medio de una permanente negociación, que incluía compensaciones materiales y reconocimientos al mérito. ${ }^{51}$

Manuel Eduardo Arias, ${ }^{52}$ comandante de los dos Escuadrones Gauchos de Orán, Santa Victoria, San Andrés y la Puna, mantuvo con Güemes una compleja relación, que concluyó en 1820. Cuando fue acusado de conspirar en su contra se refugió en Tucumán, ${ }^{53}$ cuyo gobernador estaba políticamente enfrentado con Güemes. Arias se destacó notoriamente en la guerra contra los realistas, tanto en 1814 como en 1817. Por esta razón, en 1816 fue designado por Güemes comandante de Armas de Orán. ${ }^{54}$ Sin embargo, es posible observar la autonomía con la cual opera Arias, quien toma sus propias decisiones y luego las comunica a Güemes. ${ }^{55}$ Esta actitud le ocasionará enfrentamientos, tanto con José María Pérez de Urdininea como con Francisco Pérez de Uriondo, y con jefes de milicias que integraban los Escuadrones Gauchos. Todos operaban en el mismo territorio y la relación fue por momentos tensa. Particularmente, durante el año de 1816 los problemas con Arias fueron reiterados. En el mes de julio Güemes debió ordenarle que entregara caballos para

auxiliar la partida del Capitán Rojas (...) Todas las armas, municiones y demás útiles de guerra que tenga Ud. en su poder de la pertenencia del citado Capitán Rojas, se las devolverá inmediatamente por ser propias de la dotación del regimiento del señor coronel don Juan José Fernández Campero, sin dar lugar a nuevos reclamos. ${ }^{56}$ 
En octubre, ante un conflicto entre Arias y Uriondo lo previene: "siga U a las órdenes del Teniente Coronel Uriondo (...) no me haga U. el menor movimiento de insubordinación ni desorden" ${ }^{57}$ Dos meses después, en diciembre, debe advertirle "que si el jefe de la vanguardia Sargento Mayor don José María Pérez de Urdininea le pide auxilios de carnes para la subsistencia de las tropas (...), debe Ud. franqueárselas a toda costa y sin la menor demora “. ${ }^{58}$ Obviamente, Güemes subordinaba a los jefes de las milicias a los oficiales del Ejército Auxiliar y de los Cuerpos de Línea por él organizados en la provincia de Salta. Todo indica que Arias era quien había reclutado a los gauchos que integraban sus escuadrones, al igual que aquellos que respondían a Mariano Benavídez y a Juan Antonio Rojas. La destacada actuación de Arias, en la invasión de La Serna en 1817, concluyó por convertirlo en un líder importantísimo en la vanguardia y por ello fue premiado por el director supremo Juan Martín de Pueyrredón, con el cargo de teniente coronel, y recompensado por Güemes con la entrega, supeditada a la aprobación del director supremo, de la Hacienda de Zenta. ${ }^{59}$

Cabe señalar que las tierras de otras reducciones, como las de Balbuena y Miraflores, que a diferencia de la Misión de Zenta se encontraban en zonas de antigua ocupación, próximas a la frontera del Rosario, y por ende mucho más valiosas que las de Zenta, fueron entregadas por Güemes a jefes de sus Cuerpos de Línea, miembros de la elite, para saldar deudas en ganados y contribuciones realizadas para sostener la guerra. De este modo, en 1818 José María Saravia, teniente coronel de Coraceros, ${ }^{60}$ recibió las tierras de la reducción de Balbuena ${ }^{61}$ sin que fuera necesaria la aprobación del director supremo, $y$, en 1821, luego de varios años de reclamos, ${ }^{62}$ en cancelación de deudas contraídas por la provincia de Salta, Güemes subastó a favor de José Ignacio de Gorriti las tierras de la reducción de Miraflores ${ }^{63}$ que habían sido solicitadas por José de Moldes en $1819 .^{64}$

La diferencia, aun cuando todas constituían compensaciones tendientes a conservar obediencia -y más allá de que en estos dos últimos casos las tierras fueron cedidas para saldar deudas privilegiando a los beneficiados sobre otros acreedores-, reside en que la cesión de la misión de Zenta a Manuel Eduardo Arias fue en el formato jurídico colonial de las mercedes otorgadas a los conquistadores. La autoridad de Güemes, en este caso, fue puesta a prueba por Arias al solicitarlas en un tono cautamente imperativo

\begin{abstract}
que si son llegados los felices momentos en que nuestra augusta Patria recompense el mérito de sus buenos y verdaderos hijos; también es consiguiente que la bondad de este Gobierno prodigue un rasgo de su generosidad en hacer recuerdo de sus continuos actuales desinteresados servicios que son de pública notoriedad a todos, y mucho más a VS. En cuya virtud (...) se ha de servir la justificación de VS asignarle como en premio de sus fatigas el Parage de la Misión de Zenta con todo lo perteneciente a ella... ${ }^{65}$ (énfasis nuestro)
\end{abstract}

La entrega de las tierras solicitadas comprueba cuán necesario era para Güemes mantenerlo a sus órdenes en la vanguardia. Sin embargo, al hacerlo por merced alienta la posibilidad de que dicha cesión fuera precaria, por cuanto dependía de una confirmación de parte del director supremo. Esta confirmación no se habría de concretar, y las mencionadas tierras volverían al Estado luego de que Arias se refugió en Tucumán en 1820.

A pesar de las dificultades para obtener recursos y conservar la adhesión de líderes importantes de sus milicias, como es el caso de Arias, Güemes desplegó una intensa actividad que procuraba abastecer de armamento a todas las partidas, en ocasión de enfrentar a los realistas, para lo cual solicitará reiteradamente ayuda a Manuel Belgrano, a la vez que imponía préstamos forzosos a los comerciantes de Salta y Jujuy, los cuales se irán incrementando a partir de 1818 (Marchionni, 2019).

Como jefe de la vanguardia estableció asimismo vinculaciones con las guerrillas insurgentes del Alto Perú. Ante las derrotas sufridas por estas, en 1816, y la muerte de sus principales caudillos, en febrero de 1817, Francisco de Uriondo, desde Papachacra, localidad próxima a Tarija, escribía a Güemes solicitándole nombrase a un jefe "para que se haga cargo de todas esas republiquetas y yo pueda entenderme con esos comandantes" ${ }^{66}$ Los esfuerzos de Güemes por coordinar con los grupos insurgentes, que en 1817 se nuclearon en Ayopaya, resultaron exitosos y de ello dan cuenta numerosos testimonios (Mata, 2008). 
El ejercicio de autoridad sobre esas fuerzas militares heterogéneas -compuestas por Escuadrones Gauchos, milicias locales y grupos insurgentes con sus propios líderes, junto con oficiales del Ejército Auxiliar, que, si bien lo reconocían como jefe de la vanguardia, conservaban una estrecha relación con Belgrano- permite comprobar su capacidad de negociación, la cual le facilitó coordinar con éxito, durante siete años, las acciones tendientes a conservar los territorios de vanguardia frente al Ejército Real del Perú.

\section{Reflexiones FinAles}

Durante los siete años que gobernó la provincia de Salta y fue el jefe de la vanguardia, Güemes buscó detentar la autoridad necesaria para disciplinar y coordinar tanto a las milicias como a los Cuerpos de Línea que organizara en 1816, y también a aquellas milicias y grupos insurgentes organizados previamente a 1814, y que operaban fundamentalmente en Tarija, en Cinti y en la Puna. Si bien excede los objetivos de este trabajo abordar el proceso de politización que acompañó a la militarización en Salta, cabe preguntarse en qué medida las dificultades que Güemes enfrentó para lograr obediencia y subordinación respondían a rivalidades personales, disputas territoriales y/o diferencias políticas; conflictos y rivalidades en los cuales no solo estuvieron involucrados oficiales del Ejército Auxiliar, jefes de los cuerpos de Líneas, de las milicias gauchas y de los partidarios que actuaban en el valle de Lerma y en la frontera, sino también quienes lideraban grupos insurgentes en el territorio que abarcaba la vanguardia del Ejército Auxiliar e incluso en el Alto Perú.

No caben dudas de que las disputas políticas tuvieron en algunos casos importancia y que en ellas pudieron estar presentes también problemas territoriales. Así, las desavenencias de Güemes con los oficiales del Ejército Auxiliar en 1814, y luego con el Directorio y Rondeau en 1815, que se prolongaron hasta marzo de 1816, evidencian la importancia de las disputas políticas en las relaciones de Güemes con otros jefes y oficiales bajo su mando. Entre 1814 y 1816 contó con el apoyo de los grupos adictos a los proyectos federales, que sin duda favorecieron su elección como gobernador, y la abierta oposición de quienes defendían el centralismo porteño solidarizados con Rondeau. Estos simpatizaban con los federales Pablo Latorre y José Francisco (Pachi) Gorriti, además de con los hermanos José y Eustaquio Moldes (Mata, 2017). Estrechamente vinculados con los dos primeros se hallaba Vicente Panana, quien lograría, gracias a su capacidad para movilizar voluntarios y a su demostrada valentía, ingresar con el grado de capitán a la División Infernales de Línea.

Los primeros incidentes, que dan cuenta de diferencias políticas, tuvieron lugar unos meses después de ser electo gobernador, cuando dispuso la prisión de algunos oficiales de la División Infernal de Gauchos de Línea. Entre ellos se encontraba Apolinario Saravia "incomunicado en el cuartel". ${ }^{67}$ Si bien todos los prisioneros recobraron la libertad a los pocos días, cabe preguntarse cuál fue la incidencia que en este episodio tuvo el encarnizado enfrentamiento con Rondeau. ${ }^{68}$ Resulta significativo que entre los oficiales detenidos no se encontrasen aquellos que apoyaban a la facción federal. Sin embargo, el acuerdo alcanzado con Rondeau en marzo de 1816 -la aceptación de Juan Martín de Pueyrredón como director supremo y de Manuel Belgrano como jefe del Ejército Auxiliar-indispuso a Güemes con José de Moldes, distanció a Pablo Latorre ${ }^{69}$ e impulsó a Panana a participar, junto con Eustaquio Moldes, de una frustrada conspiración contra el gobernador (Mata, 2004b; 2017). Si en 1817 Pablo Latorre se destacó al mando de la División de Infernales ${ }^{70}$ en la resistencia a la invasión del general La Serna, un año después su nombre no se encuentra en la nómina de oficiales que la integran, de acuerdo con el informe que Güemes elevó a Belgrano.

Resulta asimismo interesante conjeturar en qué medida la disolución del Ejército Auxiliar en 1820, la destitución de Pueyrredón y los conflictos de Buenos Aires y del litoral, que incluyen a las provincias vecinas, agudizaron las disidencias entre Güemes y algunos de los jefes de las fuerzas a su mando, particularmente con Manuel Eduardo Arias, y preguntarse cuánto pudo haber incidido el sordo enfrentamiento con los grupos afines al proyecto federal, sin desestimar tampoco las disputas entre ambos por el control sobre el territorio en el cual Arias poseía el poder de movilizar. 
Igualmente es sugerente considerar, en estos enfrentamientos, los esfuerzos de Martín Miguel de Güemes por organizar en 1820 el Ejército de Observación para avanzar hacia el Alto Perú por disposición de José de San Martín, quien le había designado jefe del mencionado ejército. ${ }^{71}$ Ante la falta de recursos materiales y de hombres suficientes para la expedición programada, puesto que la fuerza militar con la cual contaba residía mayoritariamente en las milicias o Escuadrones Gauchos, reacios a abandonar el territorio y acompañarlo en una expedición al Alto Perú, Güemes pidió ayuda a las otras provincias. Por estas razones aceptó participar del congreso que proponía Bustos ${ }^{72}$ en Córdoba, en búsqueda de apoyo militar y económico. ${ }^{73}$ Con la misma finalidad intentó organizar un congreso en Catamarca. A pesar de sus esfuerzos, al finalizar el año 1820, las esperanzas de contar con el respaldo de las provincias vecinas se desvanecían, mientras la situación política en Salta se complicaba. Las desavenencias con el gobernador de Tucumán propiciaron la defección de parte de sus milicias y la presión económica sobre comerciantes y propietarios rurales incrementó el malestar de la elite respecto de su gobierno.

El posicionamiento político que lo alineó con el poder centralizado en Buenos Aires, entre 1816 y 1819, lo distanció de quienes propiciaron su gobierno en 1815, sin lograr tampoco el apoyo de aquellos que lo habían resistido y lo consideraban responsable de la indisciplina social y de los "excesos del gauchaje".

\section{FuENTES CONSULTADAS}

ABHS, Fondo Documental Dr. Bernardo Frías.

ABHS, Fondo de Gobierno, Caja 35, Carpeta 1512.

ABHS, Fondo de Gobierno, Caja 33, Carpeta 1492.

ABHS, Fondo de Gobierno, Caja 33, Carpeta 1490.

ABHS, Fondo de Gobierno, Caja 36, Carpeta 1517.

ABHS, Fondo de Gobierno, Caja 33, Carpeta 1492.

ABHS, documentación del Armario Gris.

AGN, Sala X, Gobierno de Salta, 5-7-4.

AGN, Sala X, Gobierno de Salta, 5-7-3.

AGN. Sala X, División Gobierno Nacional. Congreso Nacional, 3-9-9, AGN. Sala X, Guerra, 4-1-3.

AGN. Ejército del Norte, Sala X, 43-6-3.

Güemes, L. (1980a). Güemes documentado. Buenos Aires: Plus Ultra. Tomo 3.

Güemes, L. (1980b). Güemes documentado. Buenos Aires: Plus Ultra. Tomo 4.

Güemes, L. (1979). Güemes documentado. Buenos Aires: Plus Ultra. Tomo 2.

Güemes, L. (1980c). Güemes documentado. Buenos Aires: Plus Ultra. Tomo 5.

Güemes, L. (1980d). Güemes documentado. Buenos Aires: Plus Ultra. Tomo 6.

Güemes, L. (1984b). Güemes documentado. Buenos Aires: Plus Ultra. Tomo 9.

Paz, J. M. [1857] (2000). Memorias Póstumas. Buenos Aires: Emecé Editores.

Uriburu, D. [1857] (1960). Memorias de Dámaso Uriburu. Buenos Aires. En Biblioteca de Mayo, Tomo I, pp. 621-783

Villanueva, N. (1960). Memoria sobre la campaña de Sipe-Sipe. En Biblioteca de Mayo, Tomo II Buenos Aires: Senado de la Nación. pp. 2071-2092

Weinberg, G. (2001). Epistolario Belgraniano. Buenos Aires: Turus.

\section{ReFERENCIAS}

Abbate, G., y Burgos, L. (2020). De la ciudad a la provincia. El caso de la “independencia” de Jujuy en el Río de la Plata (1811-1815).PolHis, 25, 131-163 Recuperado de http://polhis.com.ar/index.php/polhis/article/view/48/31 
Ayrolo, V., Lanteri, A. L., y Morea, A. (2011). Repensado la “Carrera de la Revolución”. Aportes a la discusión sobre las trayectorias políticas entre la Revolución y la Confederación (Argentina. 1806-1861). Estudios Históricos, 3(7), 1-28. Recuperado de http://www.estudioshistoricos.org/Otros/n07.html

Arnade, Ch. (1964). La dramática insurgencia de Bolivia. La Paz: Librería Juventud.

Arze Aguirre, R. (1979). Participación popular en la Independencia de Bolivia. La Paz: Talleres. Escuela de artes gráficas. Bourdieu, P. (2001). El campo politico. Bolivia: Plural editores.

Bourdieu, P. (1991). El sentido práctico. España: Taurus Humanidades.

Bragoni, B. (2005). Guerreros virtuosos, soldados a sueldo. Móviles del reclutamiento militar durante el desarrollo de la guerra de independencia. Dimensión Antropológica, 35, 95-138.

Colmenares, L. (1999). Martín Güemes. El héroe mártir. Buenos Aires: Ediciones Ciudad Argentina.

Cornejo, A. (1971). Historia de Güemes. Salta: Artes gráficas.

Cutolo, V. (1968-1985). Nuevo diccionario biográfico argentino. Buenos Aires: Editorial ELCHE.

Chust, M., y Marchena, J. (eds.) (2007). Las armas de la Nación. Independencia y ciudadania en Hispanoamérica (1750-1850). Madrid: Iberoamericana, Vervuet.

Davio, M. (2018). Morir por la Patria. Participación y militarización de los sectores populares en Tucumán, 1812-1854. Rosario: Prohistoria ediciones.

Di Meglio, G. (2006). ;Viva el bajo pueblo! La plebe urbana de Buenos Aires y la política entre la Revolución de Mayo y el rosismo. Buenos Aires: Prometeo libros.

Fradkin, R. (2010). Sociedad y militarización revolucionaria. Buenos Aires y el litoral rioplatense en la primera mitad del siglo XIX. La construcción de la Nación Argentina. El rol de las fuerzas armadas. Buenos Aires: Ministerio de Defensa. Presidencia de la Nación.

Fradkin, R. (2012). Guerra y sociedad en el litoral rioplatense en la primera mitad del siglo XIX. En J. C. Gravaglia, J. Pro Ruiz y E. Zimmermann (eds.), Las fuerzas de guerra en la construcción del Estado. América Latina, siglo XIX (pp. 319-356). Rosario: Prohistoria- Ediciones-SBLA.

Frega, A. (2002). Caudillos y montoneras en la revolución radical artiguista. Andes: Antropología e Historia, 13, 75-112.

Frías, B. (1971-1973). Historia del General Güemes y de la provincia de Salta. Buenos Aires: Ediciones De Palma.

Garavaglia, J. C. (2003). Ejército y milicia: los campesinos bonaerenses y el peso de las exigencias militares, 1810-1860. Anuario IEHS, 18, 167-170.

Halperín Donghi, T. (1972). Revolución y Guerra. Formación de una elite dirigente en la Argentina criolla. Buenos Aires: Siglo XXI editores.

Mamani Siñani, R. (2010). "La División de los Valles": Estructura militar, social y étnica de la guerrilla de La Paz y Cochabamba. 1814-1817. La Paz: Instituto de Estudios Bolivianos- Asdi.

Mann, M. (1991). Las fuentes del poder social. Madrid: Alianza Universidad.

Marchionni, M. (2008). Entre la guerra y la política. Las elites y los cabildos salto-jujeños en tiempos de Güemes. En B. Bragoni y S. Mata (Coords.), Entre la colonia y la república: Insurgencias, rebeliones y cultura politica en América del Sur (pp. 217-244). Buenos Aires: Prometeo.

Marchionni, M. (2019). Politica y sociedad en Salta y el Norte Argentino. Salta: ICSOH- EUCASA-Fondo Editorial Secretaría de Cultura.

Mata de López, S. (1999). “Tierra en armas”. Salta en la Revolución. En S. Mata de López (Comp.). Persistencias y cambios. Salta y el Noroeste Argentino. 1770-1840 (pp. 149-175). Rosario: Prohistoria \& Manuel Suárez editor.

Mata de López, S. (2002). La guerra de independencia en Salta y la emergencia de nuevas formas de poder. Andes: Antropolgía e Historia, 13, 113-144.

Mata de López, S. (2004). Salta (Argentina) y la guerra de independencia en los Andes Meridionales. Jahrbuch Für Geschichte, 44, 223-246. 
Mata de López, S. (2004b). Conflicto social, militarización y poder en Salta durante el Gobierno de Martín Miguel de Güemes. En F. Herrero, (Comp.), Revolución, política e ideas en el Río de la Plata en la década de 1810 (pp. 125-148). Buenos Aires: Universidad de Tres de Febrero.

Mata de López, S. (2008). Insurrección e Independencia. La Provincia de Salta y los Andes del Sur. En R. Fradkin (Ed.), ¿Y el pueblo dónde está? Contribuciones para una historia popular de la revolución e independencia en el Rio de la Plata (pp. 177-208). Buenos Aires: Prometeo.

Mata de López, S. (2009). Guerra, militarización y poder. Ejército y milicia en Salta y Jujuy. 1810-1816. Anuario IEHS, 24, 279-298.

Mata, S. (2017). Disputas políticas en tiempos de guerra. Salta 1814-1821. Pasado Abierto, 6, 201-217.

Mata, S. (2019). Poder local y territorialidad. Salta en las primeras décadas del siglo XIX. Mundo Nuevo, Nuevos mundos. Recuperado de http://journals.openedition.org/nuevomundo/75856

Morea, A. (2013). Los oficiales del Ejército Auxiliar del Perú y la construcción de la carrera de la revolución. Foro 3: La movilización militar y las formas de la política en el espacio rioplatense, 1810-1880. Programa Interuniversitario de Historia Política Recuperado de http://www.historiapolitica.com/foros/movilizacion-militar/

Morea, A. (2015a). El Ejército Auxiliar del Perú durante la conducción de José Rondeau (1814-1816): Intereses personales, conflictos políticos y necesidades de Estado. Revista de Estudios Maritimos y Sociales, 7/8(7/8), 11-33. Recuperado de https://estudiosmaritimossociales.org/archivo/n7-8/

Morea, A. (2015b). Las deserciones en el Ejército Aurxiliar del Perú durante las guerras de independencia en el Río de la Plata, 1810-1820. Una aproximación cualitativa. Americanía. Revista de Estudios Latinoamericanos. Nueva Época. Número Especial, 159-197. Recuperado de https://www.upo.es/revistas/index.php/americania

Ortiz de Rozas, V. (2017). ¿Clientelismo o representación política? El "programa” de los mediadores políticos. Reflexiones desde Argentina. Revista mexicana de ciencias politicas y sociales, 62(229), 265-296. Recuperado htt p://www.revistas.unam.mx/index.php/rmcpys/article/view/51501/51451

Paz, G. (2004). La hora del Cabildo: Jujuy y su defensa de los derechos del "pueblo" en 1811. En F. Herrero (Comp.), Revolución. Política e ideas en el Río de la Plata durante la década de 1810 (pp. 149-166). Buenos Aires: Ediciones Cooperativas.

Rabinovich, A. (2012). La militarización del Río de la Plata, 1810-1820. Elementos cuantitativos y conceptuales para un análisis. Boletín del Instituto de Historia Argentina y Americana "Dr. Emilio Ravignani", 37, 11-42.

Rabinovich, A. (2011). Obedecer y comandar. La formación de un cuerpo de oficiales en los ejércitos del Río de la Plata, 1810-1820. Estudios Sociales, 41, 41-67. Recuperado de https://bibliotecavirtual.unl.edu.ar/publicacione s/index.php/EstudiosSociales/issue/view/264

Rabinovich, A. (2013). La imposibilidad de un ejército profesional: Ramón de Cáceres y el establecimiento de procedimientos burocráticos en las fuerzas del Río de la Plata. 1810-1830. Quinto Sol, 17(1), 1-24. Recuperado de http://www.fchst.unlpam.edu.ar/ojs/index.php/quintosol

Rabinovich, A. (2012a). La máquina de guerra y el Estado: el Ejército de los Andes tras la caída del Estado central del Río de la Plata en 1820. En J.C. Garavaglia, J. Pro Ruiz y E. Zimmermann (eds.) Las fuerzas de guerra en la construcción del Estado. América Latina, siglo XIX (pp. 205-240). Rosario: Prohistoria- Ediciones-SBLA,.

Roca, J. (1984). Las masas irrumpen en la guerra (1810-1821). Historia y Cultura, 6, 1-30.

Saignes, T. (2006). Historia del pueblo chiriguano. Lima: IFEA.

Soux, M. L. (2010). El complejo proceso hacia la independencia de Charcas. Guerra, ciudadania, conflictos locales y participación indigena en Oruro. La Paz: IFEA-Plural Editores-Asdi-IEB.

Thibaud, C. (2005). Formas de guerra y mutación del ejército durante la guerra de independencia en Colombia y Venezuela. En J. Rodríguez (Coord.), Revolución, independencia y las nuevas naciones de América (pp. 233-251). Madrid: MAFRE/Tavera. 


\section{Notas}

* Investigación realizada en el marco del PIP 112 Sociedad y economía en tiempos de cambios. Salta en la primera mitad del siglo XIX y PUE CONICET 056CO, Territorialidad y poder. Conflictos, exclusión y resistencias en la construcción de la sociedad en Salta. Agradezco los comentarios y sugerencias de los evaluadores externos de la revista.

1 Cabildo de Salta, 24 de mayo de 1821, Mensaje del Cabildo de Salta a los ciudadanos [Fondo Documental Dr. Bernardo Frías, Carpeta 10. Documento 48]. Archivo y Biblioteca Históricos de Salta, (en adelante ABHS) Salta, Argentina.

2 Efectivamente, en su muerte confluyeron un conjunto de circunstancias. A la oposición cada vez más férrea de la elite salteña debe sumársele la disolución del Ejército Auxiliar, el quiebre del gobierno directorial en 1820, y los conflictos interprovinciales.

3 Los estudios más representativos sobre los movimientos insurreccionales andinos iniciados en 1810, y en particular en el Alto Perú, son entre otros los de Charles Arnade (1964), René Danilo Arze Aguirre (1979), José Luis Roca (1984), María Luisa Soux (2010), Roger Mamani Siñani (2012). Para el Rio de la Plata y la Banda Oriental, ver a Gabriel Di Meglio (2006) y Ana Frega (2002), y para Tucumán a Marisa Davio (2018), entre otros.

4 Se atendió a un abanico de problemas centrados en sus antecedentes coloniales, su organización, la movilización social, las formas de hacer la guerra, el reclutamiento y la deserción, entre otros (Thibaud, 2005; Chust y Marchena, 2007; Garavaglia, 2003; Rabinovich, 2011, 2012, 2013; Ayrolo, Lanteri y Morea, 2011; Morea, 2013, 2015a 2015b, Bragoni, 2005).

5 Martín Miguel de Güemes había iniciado su carrera militar en calidad de cadete en el Regimiento Fixo de Caballería de Buenos Aires instalado en Salta, y en 1804 se trasladó a Buenos Aires para continuar la carrera militar. Participó en las invasiones inglesas en el Escuadrón de Húsares organizado por Juan Martín de Pueyrredón.

6 En el Ejército Auxiliar del Perú tuvo una actuación destacada en la batalla de Suipacha, luego de la cual, por desavenencias con Balcarce y Castelli, fue dado de baja y regresó a Salta. A comienzos de 1812 fue reincorporado gracias a la influencia de Juan Martín de Pueyrredón, para ser nuevamente desafectado por "conducta ilícita”, a comienzos de 1813, por Manuel Belgrano.

7 Las fuerzas lideradas por Güemes incluyeron a los milicianos a sueldo que custodiaban los fuertes de la frontera chaqueña, las milicias voluntarias organizadas por referentes locales, las partidas comandadas por oficiales del Ejército Auxiliar y los Cuerpos de Línea creados por el gobernador de Salta (Mata, 2009).

8 En particular, Bernardo Frías (1971-1973), Atilio Cornejo (1971) y Luis Colmenares (1999). Abogados, escribanos y periodistas, entre otros interesados en el tema, han publicado numerosos textos que han fortalecido esta idea.

9 José María Paz (1885) Memorias Póstumas. (2000, Buenos Aires: Emecé, p. 157-158.); Cabildo de Salta, 24 de mayo de 1821, Mensaje del Cabildo de Salta a los ciudadanos [Fondo Documental Dr. Bernardo Frías, Carpeta 10. Documento 48]. Archivo y Biblioteca Históricos de Salta, ABHS, Salta, Argentina

10 José de Rondeau, Concha, 15 de setiembre de 1814, Oficio al Director Supremo [Güemes, L (1979) p. 207-208]

11 Los Partidarios eran cuerpos regulares que formaban parte de los fuertes de la frontera chaco-salteña. Pablo Latorre había participado en la defensa de Buenos Aires en ocasión de las invasiones inglesas; se había sumado en Salta al Ejército Auxiliar con el grado de capitán en 1810, y tomó parte en la batalla de Salta en 1813 (Cutolo, 1975, vol. IV, p. 120)

12 Manuel Dorrego, Guachipas, 2 de febrero de 1814, Oficio a José de San Martín (Güemes, L. (1979), p. 72-73)

13 La solicitud de San Martín en diciembre de 1813 para que Güemes fuera designado teniente coronel pudo deberse a las recomendaciones de Pueyrredón, pero también a la posibilidad de otorgarle un lugar importante en el ejército a su mando.

14 Eustaquio Díaz Vélez, 1 de abril de 1813, Socorro a Vicente Martínez (alias Panana) por los buenos servicios que ha hecho a la Patria (Sala X, Ejército del Norte, 43-6-3) Archivo General de la Nación, (en adelante AGN), Buenos Aires, Argentina.

15 Cabildo de Salta, 29 de octubre de 1814. Acta de Cabildo (Güemes, L. (1979), p. 247)

16 Sobre la importancia de la formación de una oficialidad en la organización de los ejércitos revolucionarios y las formas de incorporación a la misma véase Alejandro Rabinovich (2011) y Alejandro Morea (2013).

17 Atacama, partido perteneciente a la Provincia de Potosí, luego de ser recuperada del poder realista en 1816, decidió incorporarse a la vanguardia del Ejército Auxiliar bajo la conducción de Güemes (Mata, 2019).

18 Martín Miguel de Güemes, Jujuy, setiembre 17 de 1814. Oficio a Martín Rodríguez (Güemes, L. (1979), p. 317)

19 Gobierno de Buenos Aires, Borrador de Oficio a José Rondeau, Buenos Aires, octubre 15 de 1814 (Güemes, L. (1979), p.318-319)

20 Las disputas por el control y organización de las milicias se agudizaron con la disposición de Rondeau, también fracasada, de encomendar dicha tarea a José Antonino Fernández Cornejo, a quien había nombrado gobernador de la provincia de Salta (Mata, 2002). 
21 Si bien se movilizaron milicias en 1810, estas no fueron muy numerosas. Previo a 1814, Belgrano había denunciado el escaso entusiasmo de la población rural por la revolución.

22 Efectivamente, Hilarión de la Quintana, designado por Rondeau gobernador de Salta, marchó junto con el ejército hacia el Alto Perú y delegó en el Cabildo algunas de las prerrogativas de gobierno.

23 Cabildo de Salta, 6 de mayo de 1815, Acta de Cabildo (Güemes, L. (1979), p. 364)

24 Martín Miguel de Güemes Salta, 12 de setiembre de 1815, Oficio al Director Supremo (Güemes, L. (1980a), p.210-211)

25 Beatriz Bragoni (2005) ha señalado la importancia del salario para reclutar y disciplinar a las tropas.

26 Panana muestra las posibilidades y los límites de ascenso social que ofrecía la guerra y la dinámica de la movilización, así como también las disputas políticas que atravesaban el período, particularmente a partir de 1814 (Mata, 2004b).

27 Martín Miguel de Güemes Salta, 12 de setiembre de 1815, Oficio al Director Supremo (Güemes, L. (1980a), p.210-211)

28 El teniente de gobernador de Jujuy denunciaba en agosto de 1815 ante las autoridades de Buenos Aires la resistencia que había ofrecido Güemes a la organización de las milicias en Jujuy donde él tenía “...alistadas en la campaña más de seiscientas personas en precaución”. Oficio del Teniente de Gobernador de Jujuy al Director Supremo, Jujuy, agosto 24 de 1815. Güemes, L. (1979), pp. 483-484.

29 A comienzos de 1816, Rondeau, con el derrotado Ejército Auxiliar del Perú y el apoyo de la elite sato-jujeña, opositora a Güemes, ocupó la ciudad de Salta y destituyó a Güemes como gobernador. La ciudad fue sitiada por los escuadrones gauchos (Mata, 2004).

30 Cabildo de Jujuy, 3 de febrero de 1816. Acta de Cabildo (Güemes, L. (1980a), p.266-267)

31 La derrota infringida a las partidas del Ejército Auxiliar obligó a Rondeau finalmente a celebrar con Güemes un pacto por el cual convenían cooperar unidos para enfrentar a las fuerzas realistas y admitían la incorporación de oficiales y tropas a las fuerzas militares de la provincia de Salta.

32 Mariano de Gordaliza, Jujuy abril 17 de 1816, Oficio al Director Supremo (Güemes, L. (1980a), p.342-343)

33 Martín Miguel de Güemes, Cuartel General de Chicuana, Marzo 18 de 1816, Carta a Mariano Benavidez (Sala X, Guerra, 4-1-3) AGN, Buenos Aires, Argentina

34 Lista de los señores oficiales que se comprenden en el estado general de la fuerza militar de la provincia de Salta en esta fecha, Salta octubre 15 de 1818, Güemes, L. (1984a), pp. 22-43. De acuerdo con este informe, sobre un total de 4.888 hombres que integraban los Escuadrones Gauchos, 2.090 pertenecían a los 5 Escuadrones del valle de Lerma.

35 Martín Miguel de Güemes, Salta, abril de 1818, Bando (Sala X, Gobierno de Salta, 5-7-4) AGN, Buenos Aires, Argentina

36 María Juliana González, Salta, abril de 1817. Solicitud al Sr. Coronel y Gobernador Intendente (Fondo de Gobierno, Caja 33, Carpeta 1492) ABHS, Salta, Argentina; Martín Miguel de Güemes, Salta, 1818. Oficio al Director Supremo (Sala X, Gobierno de Salta, 5-7-3) AGN, Buenos Aires, Argentina

37 Pablo Martearena, Jujuy, 3 de enero de 1818. División de Gauchos Arrieros. Razón del dinero que se necesita para el socorro semanal de los individuos de ella (Fondo de Gobierno. Caja 35, Carpeta 1512) ABHS, Salta, Argentina.

38 Manuel Belgrano, Tucumán, 26 de setiembre de 1817. Carta a Martín Miguel de Güemes (Weinberg, 2001, p. 333-334)

39 Martín Miguel de Güemes, Salta, mayo 20 de 1817. Oficio a José Antonino Fernández Cornejo (Gúemes, L (1980b) p. 383-384) Propietario de una importante hacienda en Campo Santo, en la frontera con el chaco de antigua ocupación, Fernández Cornejo mantenía una vieja rivalidad con Martín Miguel de Güemes. Combatió en la batalla de Salta en febrero de 1813 y en 1814 fue nombrado gobernador de la provincia por José Rondeau. Comandante del Regimiento de Partidarios de Salta participó de la guerra librada en Salta entre 1815 y 1821.

40 Martín Miguel de Güemes, Salta, 16 de Octubre de 1820. Auto arrendamiento de gauchos (Armario Gris) ABHS, Salta, Argentina

41 Bartolomé de la Corte, Jujuy, diciembre 7 de 1816. Oficio a Eustaquio Medina (Güemes, L. (1980b) p.154)

42 Tarija integraba la jurisdicción de la provincia de Salta, de modo que era totalmente razonable quedase a cargo de Güemes.

43 José Rondeau, Cuartel General en Jujuy, 30 de octubre de 1814. Oficio a Juan Antonio Alvarez de Arenales (Güemes, L. (1979) p.250).

44 En 1814 Carlos de Alvear había sido designado jefe del Ejército Auxiliar, cargo que no asumió por la oposición de parte de los oficiales del mencionado ejército, entre los cuales se encontraba José Rondeau. El malestar entre los oficiales que habían apoyado a uno y otro jefe persistió en las filas del Ejército (Morea, 2015a)

45 Nicolás Villanueva, Memoria sobre la campaña de Sipe-Sipe (Biblioteca de Mayo, Tomo II, p. 2078)

46 José María Pérez de Urdininea era natural de La Paz y se sumó al Ejército Auxiliar en 1811. A las órdenes de Belgrano combatió en la batalla de Tucumán (1812) y de Salta (1813) y continuó en el Ejército Auxiliar a las órdenes de Rondeau. En 1816 y 1817 fue jefe de la retaguardia del Ejército Auxiliar en la quebrada de Humahuaca. Luego del retiro del general La Serna hacia el Alto Perú se alejó del Ejército Auxiliar para sumarse al Ejército de los Andes (Cutolo, 1978, Tomo V, p. 440) 
47 Francisco Pérez de Uriondo era natural de Chile y desde 1810 se unió a la revolución en el río de la Plata. Participó del sitio de Montevideo y en 1815 se sumó al Ejército Auxiliar. Luego de la derrota y en la retirada hacia Tucumán decidió permanecer en Salta (Cutolo, 1978, Tomo V, p.441).

48 José María Pérez de Urdininea, Campo Santo, Febrero 7 de 1817. Parte al Sr. Coronel General de la Vanguardia Martín Miguel de Güemes (Güemes, L. (1980b) p. 307)

49 Francisco de Uriondo, Villa de Tarija, 15 de noviembre 1816. Oficio a Martín Miguel de Güemes (Güemes, L. (1980b) p.148-150)

50 Los grupos insurgentes se reorganizaron en 1817 en Ayopaya, luego de las derrotas sufridas por Camargo, Padilla, Betanzos y tantos otros en 1816. Fueron sus jefes, Lira y luego Chinchilla, quienes reconocieron a Güemes como jefe de vanguardia del Ejército Auxiliar y con quien mantenían comunicación (Mata, 2008).

51 Varios, Salta, año 1817. Solicitud de socorros (Fondo de Gobierno, Caja 35, Carpeta 1512) ABHS, Salta, Argentina; Martín Miguel de Güemes, abril de 1817. Disposiciones del Señor Gobernador (Fondo de Gobierno, Caja 33, Carpeta 1492) ABHS, Salta, Argentina.

52 Manuel Eduardo Arias era mestizo y natural de Jujuy. Se sumó a la revolución desde 1810 y en 1814 era ya capitán de milicias voluntarias en la quebrada de Humahuaca (Cutolo, 1968,Tomo I, p. 226).

53 Martin Torino, Salta, 4 de enero de 1820. Carta a Juan Marcos Zorrilla (Güemes, L. (1984) p.195-196)

54 Cabildo de Orán, 27 de mayo de 1816. Acta de Cabildo (Güemes, L. (1980a) p.387-388)

55 Martín Miguel de Güemes, Salta, junio 5 de 1816. Oficio a Manuel Eduardo Arias (Güemes, L. (1980a) p.390)

56 Martín Miguel de Güemes, Salta, julio 20 de 1816. Oficio a Manuel Eduardo Arias (Güemes, L. (1980b) p.29-30)

57 Martín Miguel de Güemes, Salta, octubre 2 de 1816. Respuesta al oficio de Manuel Eduardo Arias (Fondo de Gobierno, Caja 33, Carpeta 1490) ABHS, Salta, Argentina.

58 Martín Miguel de Güemes, Salta diciembre 7 de 1816. Oficio a Manuel Eduardo Arias (Güemes, L. (1980b) p.153)

59 Manuel Eduardo Arias, Orán, abril 7 de 1818. Solicitud de merced en Orán (Fondo de Gobierno, Caja 36, Carpeta 1617) ABHS, Salta, Argentina

60 En 1818, Martín Miguel de Güemes era Capitán de Coraceros y, en segundo lugar, como teniente coronel revistaba José Maria Saravia.

61 José María Saravia, noviembre 10 de 1818. Solicitud de donación de las tierras de la reducción de Balbuena (Güemes, L. (1980c) p. 375-376)

62 José Ignacio Gorriti, Tucumán, julio 26 de 1816. Carta a Juan Manuel Quiroz (Güemes, L. (1980a), p. 484-486)

63 José Ignacio Gorriti, Salta, 13 de agosto de 1814- 3 de marzo de 1821. Expediente de adjudicación de la reducción de Miraflores (Fondo Documental Güemes. Documento 16) ABHS, Salta, Argentina.

64 Juan Antonio Moldes. Salta, 10 de octubre de 1819. Solicitud de donación de la reducción de Miraflores (Sala X. 3-9-9. División Gobierno Nacional. Congreso Nacional) AGN, Buenos Aires, Argentina

65 Manuel Eduardo Arias, Orán, abril 7 de 1818. Solicitud de merced en Orán (Fondo de Gobierno, Caja 36, Carpeta 1617) ABHS, Salta, Argentina

66 Francisco de Uriondo, Campamento de Papachacra, febrero 16 de 1817. Oficio a Martín Miguel de Güemes (Güemes, L. (1980b), p. 351-352)

67 Bernabé Aráoz, Tucumán, 11 de noviembre de 1815. Oficio al Director Supremo (Güemes, L. (1980a), p.80-82)

68 En noviembre de 1815 Güemes dudaba en autorizar el paso de 2000 hombres que, a las órdenes de French, se dirigían hacia Jujuy para sumarse al Ejército Auxiliar, que aún se encontraba en Tupiza (Mata, 2002).

69 Manuel Belgrano, Tucumán, 10 de agosto de 1817. Carta a Martín Miguel de Güemes (Güemes, L. (1984d), p. 271-272)

70 Ejército Auxiliar del Perú, Desde 10 de abril de 1817 hasta el 30 del mismo. Boletín 20. [Güemes, L. (1980b), p. 453-454.]

71 El contexto político en el Río de la Plata entorpecía los planes de José de San Martín. La designación de Güemes por parte de San Martin es un indicio claro de la crisis política que atravesaba el proceso revolucionario iniciado en 1810 (Rabinovich, 2012a, pp. 220-221).

72 Juan Bautista Bustos, natural de Córdoba, formaba parte del Ejército Auxiliar del Norte. Nombrado Jefe del Estado Mayor del mencionado ejército se sublevó en Arequito y se retiró a Córdoba; poco después fue nombrado gobernador de Córdoba, donde organizó un congreso constituyente.

73 En el Cabildo extraordinario, citado con la finalidad de evaluar la solicitud de Bustos, Güemes manifestó "que el sentir había sido, se nombrase un diputado que pasare a Córdoba, para que en unión de los de las demás provincias procurase transar las diferencias entre Buenos Aires, Santa Fe y la Banda Oriental, como igualmente procurase la organización de un ejército o expedición contra el enemigo común, aumentando aquel ejército... (el énfasis es nuestro). Cabildo de Salta, 29 de febrero de 1820. Acta de la Asamblea Electoral de Salta. [Güemes, L. (1984) p.256-257]. 